\title{
AIDS debate continues
}

SIR - G. Garnett and R. Anderson (Nature 366, 716; 1993) make erroneous comments on our unpublished scientific data. Both ethics and etiquette demand that permission should be obtained by authors before citing unpublished work of others, but the authors did not do so on this occasion.

I emphasize that we are not involved in a research programme on AIDS in Africa, or elsewhere. Instead, we are concerned with a high-frequency cancer, Burkitt's lymphoma, of children in Africa; I have visited Malawi on several occasions to organize these investigations. Routinely, in order to ascertain how to handle safely in our London laboratory the biopsy materials received from Malawi, blood samples from the same children have been screened for two viruses, hepatitis-B virus (HBV) and HIV. Since 1987, around 300 such samples have been analysed.

Our findings, as mentioned informally to Anderson, are that whereas about 14 per cent of these are positive for the very infectious $\mathrm{HBV}$, only about 1-2 per cent per year are positive for HIV - a figure unchanged over the 6-year period 1987 92. The number of patients with Burkitt's lymphoma seen over this same period in a single hospital in Malawi has increased by nearly 100 per cent. Patients range in age from 1 year to early teens, with a median age of about 6 . Many, but by no means all, of these children come from rural areas.

Garnett and Anderson thus distort our data. Anderson believes our findings could be explained by the fact that HIVpositive children would have died before reaching the age when they might have developed Burkitt's lymphoma. This remains a possibility but is an unlikely explanation. I have offered the alternative explanation of a rural bias, with the caveat that if this were the case, then figures on HIV-positivity for entire countries such as Malawi could not, and should not, be deduced from urban data.

Garnett and Anderson further state that "Malawi is not a country from which data on the prevalence of HIV are readily available". This seems a misrepresentation. Their own review article (R. M. Anderson et al. Nature 352, 581-589; 1991; Table 1) cites HIV figures for Malawi as: weighted mean per cent seroprevalence, 17.0 ; number of surveys, 19 ; total number of people tested, 7,736; estimated urban population size, 1 million. (The total population of Malawi is nearly 10 million.) There are various other papers dealing with HIV in Malawi, including those of P. J. Miotti and colleagues (Johns Hopkins University School of Hygiene and Public Health) drawn from data derived from women in an antenatal clinic at a major urban hospital there, and a con- trol case study (J. M. Pönnighaus and others) from the leprosy evaluation project in the rural northern part of Malawi.

Readers may ask why we have not yet published our own data. There are several explanations. One, we did not set out to study HIV, the presence of the virus being possibly relevant, but incidental, to our work on Burkitt's lymphoma. The presence of the virus is, however, relevant to safe sample handling. Our studies are continuing and not yet complete, and we have not sought permission from the local government to publish them. Further, and also important, many African countries resent the apparent deception practised on them with regard to HIV statistics (D. Serwadda and E. Katongole-Mbidde, Lancet 335, 842-843; 1990). We respect these sentiments, and would prefer to be on safe ground rather than rushing into print with apparently sensational, preliminary information.

Burkitt's lymphoma in children is at least as great a human tragedy as AIDS in Malawi or elsewhere in Africa, but there is very little funding for research on this topic. Are our priorities right?

\section{Beverly Griffin}

Department of Virology,

Royal Postgraduate Medical School, London W12 ONN, UK

SIR - I welcome Nature's innovative approach to handling a systematic bias by a major London newspaper, as stated in the article "New-style abuse of press freedom" $(\mathbf{3 6 6}, 493 ; \mathbf{1 9 9 3 )})$. It is impossible to think of a disease that has been as politicized as AIDS by both conservatives and liberals, often in an attempt to advance a hidden or not so hidden agenda. It is therefore imperative to promote an accurate understanding of HIV infection and AIDS among scientific and medical professionals, as well as the lay public.

The article condemning the media bias of The Sunday Times has, perhaps inadvertently, fallen victim to another aspect of HIV infection subject to numerous political agendas: the reference to "those who consider the discomforts of "safe sex' to be tiresome encumbrances" suggests great efficacy of the condom in decreasing HIV transmission.

The second-year (preclinical) medical students at the University of Arizona held a similar view of the condom, in that 89 per cent of the class believed the efficacy to be 98 per cent or higher. Ironically, some of them may well be the result of condom failures for the prevention of pregnancy. A recent meta-analysis of population-based studies of the efficacy of the condom in decreasing HIV transmission yielded an estimated efficacy of approximately 70 per cent ${ }^{1}$, similar to the
$50-90$ per cent reduction in transmission noted for circumcision (reviewed in ref. 2). Interestingly, circumcision has seldom been touted for potential reduction of HIV transmission, even though it does not depend on patient compliance. Presumably this is because circumcision is less politically correct than condoms.

It is also interesting that a survey of the sexual practices of youth in Baltimore after the revelation of the HIV positivity of the basketball player Magic Johnson showed that condom use did not change, but the number of sex partners decreased $^{3}$. It may be that the condomania of the early 1990 s is only partly justified, and that a broad range of interventions should be considered in the effort to control the HIV pandemic.

\section{Rodney D. Adam}

University of Arizona Health Sciences Center, Tucson, Arizona 85724, USA

1. Weller, S. C. Soc. Sci. Med. 36, 1635-1644 (1993) 2. Kreiss, J. K. \& Hopkins, S. G. J. inf. Dis. 168, 1404-1408 (1993)

3. MMWR 42, 45-48 (1993)

SIR - I read your attack on The Sunday Times and the reply in that paper. Many people are worried, asking for the case to be properly studied. The unfalsifiability of the HIV hypothesis is at the core of the attack on it, yet there seems to be little genuine response to the objection.

The inclusion of positive HIV status within the diagnostic criteria of AIDS is a classic popperian ad hoc move. That inclusion is often implicit in the writings of the pro-HIV lobby but sometimes also explicit. Duesberg reasons that HIV must not be included as part of the diagnosis, and then, looking at the research, concludes that it is not a cause. That case now stands in a logically superior position to the HIV hypothesis. The worry is that to save the HIV hypothesis an absurd sleight of hand has been performed.

\section{K. Ghattas}

\section{Harley Street, London W1N 1DD, UK}

SIR - I am delighted to see you taking up the cudgels with such rigour and righteousness on behalf of responsible press reporting. With reference to the annotation under the title of your leading article, a British scientific journal, Nature, has so consistently misrepresented the issues of animal welfare, animal rights and wildlife conservation and protection that a group of nongovernmental organizations plan to monitor its future treatment of these issues, if only to save their members the trouble of buying it.

The 'device' you have offered for combating this problem is promising and can equally be adopted by those affected or offended by Nature's biased reporting.

\section{Sidney J. Hoit}

Podere II Falco,

06062 Città della Pieve (PG), Italy 